CZASOPISMO INŻYNIERII LĄDOWEJ, ŚRODOWISKA I ARCHITEKTURY JOURNAL OF CIVIL ENGINEERING, ENVIRONMENT AND ARCHITECTURE

JCEEA, t. XXXIII, z. 63 (3/16), lipiec-wrzesień 2016, s. 151-158

\author{
Marek KAMIENIARZ ${ }^{1}$
}

\title{
NOWATORSKIE I EKOLOGICZNE BUDOWNICTWO Z GLINY
}

\begin{abstract}
W opracowaniu nakreślono zarys budownictwa naturalnego , pokazując najistotniejsze właściwości materiałów ekologicznych w odniesieniu do energii pierwotnej. Przedstawiono charakterystykę słomy i gliny jako materiału budowlanego. Opisano dwa przykłady technik wznoszenia budynków mieszkalnych z gliny, obecnie bardzo popularnych w Polsce i na świecie. Szczególnie zwrócono uwagę na metodę wznoszenia ścian $\mathrm{z}$ mieszanki gliny i słomy w deskowaniu tynkowanych gliną, pokazując ją na przykładzie budynku w Karniowicach. Przedstawiono także technologię wznoszenie ze słomy w nowatorskiej metodzie, przy pomocy modułów drewniano-słomianych tynkowanych gliną.
\end{abstract}

Słowa kluczowe: naturalne budownictwo, glina, słoma, energia pierwotna

\section{Wstęp}

Termin budownictwo ekologiczne nie jest jeszcze zbyt popularny w Polsce, jak również w Europie. Używa się go często jako przykład budownictwa wykorzystującego naturalne materiały budowlane, tzn. zdrowe i energooszczędne. Budownictwo ekologiczne wysoko ceni materiały jak najmniej przetworzone więc takie, które mają jak najmniejszą energię pierwotną (PEI) czyli energię, która jest potrzebna do produkcji materiału budowlanego [1]. Energia ta zawiera wszystkie procesy transportowe i produkcyjne potrzebne do uzyskania gotowego produktu. Bardzo niskie wartości PEI mają przede wszystkim materiały naturalne, natomiast produkty otrzymane przemysłowo-wyższe. Na poniższym rys.1 podano wartości PEI dla wybranych materiałów budowlanych, porównując je z produktami naturalnymi. Odczytując wartości liczbowe poszczególnych materiałów widzimy, że budownictwo ekologiczne używając produktów naturalnych znacznie mniej zanieczyszcza otoczenie naturalne niż budownictwo konwencjonalne, oparte na materiałach przetworzonych.

\footnotetext{
${ }^{1}$ Marek Kamieniarz, Politechnika Krakowska, Zakład Budownictwa i Fizyki Budowli , ul. Warszawska 24,31-155 Kraków; tel.126282152; marek109@vp.pl
} 


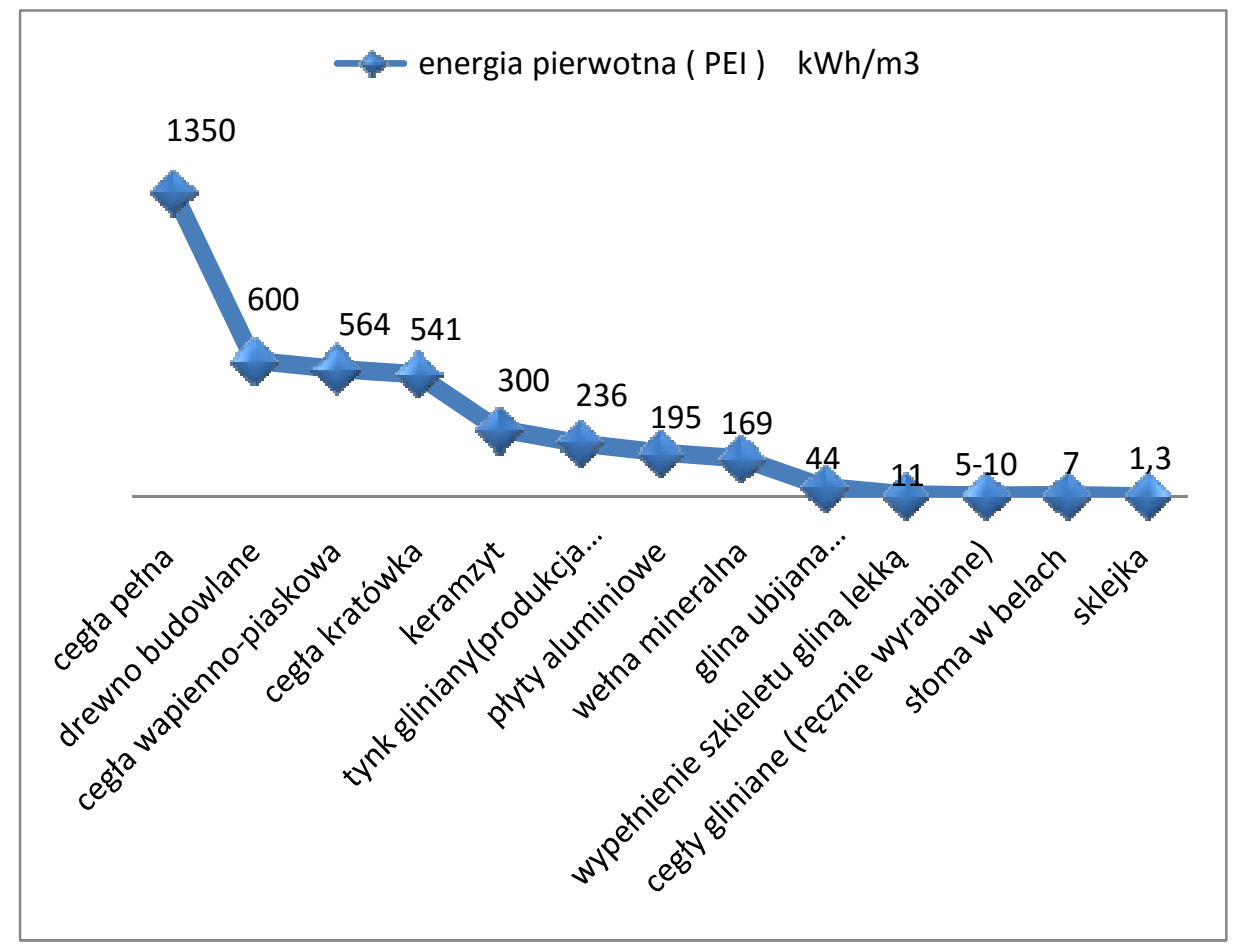

Rys. 1. Porównanie niektórych materiałów budowlanych w zależności od energii pierwotnej

Fig. 1. Comparison few building's materials depending on primary energy

\section{Krótki rys historyczny budownictwa naturalnego}

Już w kulturze starożytnej głównymi budulcami stosowanymi powszechnie $\mathrm{w}$ budownictwie były surowce naturalne $\mathrm{z}$ bezpośredniego otoczenia terenu budowy - głównie kamień, ziemia, drewno i glina. Budowano wówczas ściany $\mathrm{z}$ łączonych pionowo i poziomo elementów drewnianych, wypełnianych np. słomą, trzciną czy gliną [2]. Następnie na siatkę rzucano z obu stron kilku centymetrową warstwą gliny. Obecnie spotyka się jeszcze tą technikę budowania w krajach Afryki. Natomiast w krajach wysoko rozwiniętych, technika ta doczekała się mocno udoskonalonej wersji. Przykładem tego może być metoda prasowanej słomy wypełniającej szkielet drewniany, otynkowanej obustronnie tynkiem z gliny. Została ona zastosowana po raz pierwszy pod koniec XIX wieku w stanie Nebraska w USA. Jednak dopiero w latach 90 XX wieku w Europie i USA nastąpił powrót do tego sposobu budownictwa, głównie z powodu wzrastającej konieczności ochrony środowiska i kryzysu energetycznego. Sytuacja ta spowodowała wprowadzenie nowoczesnych rozwiązań technicznych, także w Polsce, gdzie w 1962 roku wydany został komplet norm dla budownictwa glinianego, aktualny do dziś. 


\section{Wstęp do charakterystyki materiału naturalnego}

Budownictwo ekologiczne wysoko ceni materiały jak najmniej zmienione, przykładem tego może być drewno budowlane - ale także materiały naturalne: jak słoma czy glina. Badania naukowe dowiodły, że materiałem w który warto inwestować jest słoma, mająca bardzo dobre parametry techniczne.

\subsection{Podstawowe specyfikacje techniczne słomy}

Słoma jest surowcem odnawialnym pochodzenia roślinnego - organicznego. Jest wyrobem ubocznym produkcji roślinnej w gospodarstwach rolnych. Zgodnie z Małą Encyklopedią Rolniczą [3] słoma to dojrzałe lub wysuszone źdźbła roślin zbożowych, strączkowych, lnu, rzepaku. Głównym składnikiem jej jest włókno surowe i związki bezazotowe wyciągowe. W Polsce rocznie produkuje się około 25-33 mln ton słomy [4,5]. Podstawowym kierunkiem wykorzystania słomy jest jej zagospodarowanie w rolnictwie. Jednak po odliczeniu zapotrzebowania na ściółkę i paszę oraz niezbędnej ilości na przyoranie, pozostają znaczne nadwyżki słomy, które według różnych źródeł określa się na poziomie ok. 8-12 mln ton rocznie co stwarza możliwość wykorzystania ich np. w budownictwie. Tymczasem nie ma żadnych uregulowań prawnych dotyczących kostki ze słomy, nie jest zaaprobowana jako wyrób budowlany, a technologia strawbale nie posiada normy technicznej. Można jedynie odnaleźć kilka informacji na temat stosowania słomy w budownictwie zawartych w normach $\mathrm{z}$ lat 60-tych, gdzie figuruje ona jako dodatek organiczny (wypełniacz) do mas glinianych lub cementowo glinianych. Dlatego polscy projektanci, inwestorzy bazują przede wszystkim na zagranicznych normach pod kątem zastosowania słomy jako materiału budowlanego. I tak w Niemczech na podstawie danych firmy FASBA [6], testach laboratoryjnych przeprowadzonych na kostkach słomy w poniższych jednostkach:

- testy właściwości akustycznych - w IAB w Oberursel,

- testy właściwości termicznych - w FIW Munchen,

- testy odporności pożarowej - w IBMB w Braunschweig,

- testy nośności ściany konstrukcyjnej z kostek słomy - w FEB Universitat Kassel,

- testy wilgotnościowe, biologiczne - w IBP Fraunhofer w Stuttgart oraz w ZUB.

Uzyskano aprobatę techniczną jako wyrób budowlany, a technika tynkowanej ściany z kostek słomy uzyskała generalną aprobatę techniczną i została dopuszczona do stosowania na rynku niemieckim. Poniżej pokazano kilka charakterystyk technicznych na podstawie Z-23.II-1595 - niemieckiej generalnej aprobaty technicznej [7] dla kostek słomy w zestawie z konstrukcją drewnianą jako wypełnienie ścian $w$ różnych wariantach wykończenia powierzchni wewnętrznej i zewnętrznej przegrody:

$\lambda=0,052 \mathrm{~W} /(\mathrm{mK})$ - w poprzek włókien kostki słomy

$\lambda=0,080 \mathrm{~W} /(\mathrm{mK})$ - wzdłuż włókien kostki słomy 
$\mathrm{R}=46 \mathrm{~dB}$ - izolacyjność akustyczna w warunkach laboratoryjnych

$\mathrm{R}=44 \mathrm{~dB}$ - izolacyjność akustyczna obliczeniowa

F-30-B - certyfikowana odporność ogniowa ściany z kostki słomy tynkowanej obustronnie trójwarstwowym tynkiem glinianym o grubości $3 \mathrm{~cm}$.

We Francji Agencja Jakości Budownictwa (AQC) zatwierdziła normy branżowe dla konstrukcji słomianych, opracowanych przez Francuską Sieć Konstrukcji ze Słomy (RFCP) [8]. Zakres objęty niniejszymi normami to :

- funkcja rusztu dla tynku glinianego i tynku wapiennego,

- wypełnienie przegrody kostką słomianą o funkcji izolacji termicznej,

- dla masy $80-120 / \mathrm{m}^{3} \lambda=0,052 \mathrm{~W} /(\mathrm{mK})$ prostopadle do włókien,

- przenikalność pary wodnej : 2 .

Natomiast w Wielkiej Brytanii ośrodek badawczy przy uniwersytecie w Bath opatentował technologię MODCELL [9] (Patent No. GB2457891B)33

$\mathrm{U}=0.13 \mathrm{~W} / \mathrm{m}^{2} \mathrm{~K}$ - dla słomy grubości $49 \mathrm{~cm}$

$\mathrm{R}=50 \mathrm{~dB}$ - dla ww. ściany

A+ - klasa energetyczna wyrobu

ponad $2 \mathrm{~h}$ - odporność ogniowa kostki słomianej + obustronny tynk wapienny $3 \mathrm{~cm}$

Powyższe parametry techniczne słomy wskazują jednoznacznie, że jest to materiał budowlany, mogący rywalizować z tradycyjnymi materiałami budowlanymi.

\section{Techniki budownictwa $\mathrm{z}$ gliny}

Aktualnie istnieje co najmniej kilkanaście metod budownictwa glinianego, ale najbardziej rozpowszechnionych o których warto wspomnieć jest kilka :

- wznoszenie ścian z mieszanki gliny i słomy w deskowaniu,

- wznoszenie ścian z kostek słomianych tynkowanych gliną,

- ubijanie ścian monolitycznych z mieszanki lekkiej gliny z dodatkami mineralnymi,

- formowanie prasowanych cegieł wypełniających szkielet drewniany,

- zagęszczanie suchej gliny piaszczystej ze żwirem w szalunku.

$\mathrm{W}$ ostatnich latach zmieniły się gruntownie warunki rozwoju współczesnej nowej generacji budownictwa $\mathrm{z}$ gliny. Zwiększone wymagania dotyczące ochrony cieplnej budynków (tabela 1) spowodowały, że ściany konstrukcyjne z gliny stały sie grube i ciężkie, a tym samym mniej korzystne w zastosowaniu. $\mathrm{Z}$ tego powodu odpowiednimi obecnie metodami budowania $\mathrm{z}$ gliny stały się przytoczone poniżej.

\subsection{Metoda wznoszenie ścian $\mathrm{z}$ mieszanki gliny i słomy $\mathrm{w}$ deskowaniu}

Technika ta zwana również budownictwem $\mathrm{z}$ gliny lekkiej jest to mieszanina gliny i słomy o gęstości mniejszej niż $1200 \mathrm{~kg} / \mathrm{m}^{3}$ według DIN 18951. Jeżeli natomiast ta gęstość jest większa mówimy wówczas o glinie ze słomą. Jako skład- 
Tabela 1 Wymagania izolacyjności termicznej ścian obowiązujące od $1974 \mathrm{r}$.

Table 1 Thermal insulation's requirements of wall which have applied since 1974

\begin{tabular}{|c|c|}
\hline \multirow{2}{*}{ Rok budowy } & $\begin{array}{c}\text { Współczynnik przenikania ciepła } \\
\mathbf{U}\left[\mathbf{W} / \mathbf{m}^{2} \mathbf{K}\right] \\
\text { dla ściany }\end{array}$ \\
\hline do 1974 & 1.42 \\
\hline do 1982 & 1.16 \\
\hline do 1991 & 0.75 \\
\hline do 1998 & 0.55 \\
\hline \multirow{2}{*}{ po 1998} & 0.5 \\
\hline do2013 & 0.3 \\
\hline od 2014 & 0.3 \\
\hline
\end{tabular}

nik używa się słomy żytniej, pszennej lub owsianej natomiast do tynków najbardziej nadaje się słoma jęczmienna. Ważniejsza jest jednak od rodzaju słomy struktura jej źdźbła. Dla uzyskania lepszej izolacyjności cieplnej lepiej jest zastosować słomę prostą jak najmniej pogniecioną o stabilnej łodydze, która nie została sprasowana w bele. $\mathrm{W}$ ostatnich kilku latach zbudowano dużo budynków mieszkalnych z lekkiej gliny, gdzie grubość ściany wahała się w granicach $30 \mathrm{~cm}$. Badania wykazały, że oczekiwana niska gęstość ścian z gliny wynosząca ok. 300 do $400 \mathrm{~kg} / \mathrm{m}^{3}$ nie została osiągnięta z przyczyn:

- słoma sprasowana w belach zawiera za mało pustych przestrzeni,

- słoma zatopiona w masie jest miękka i zgnieciona, co powoduje, że masa już w fazie przygotowania i składowania zostaje stosunkowo mocno zagęszczona, - podczas wkładania mieszanki w deskowanie następuje kolejne zagęszczanie.

Według badań przeprowadzonych przez Laboratorium Budownictwa Eksperymentalnego w Kassel (FEB) najlżejsza mieszanka wykonana z prasowanej słomy o długości zalecanej 10 do $15 \mathrm{~cm}$, waży ok. $500 \mathrm{~kg}$. Taka nie wykazuje wystarczającej wytrzymałości, dla np. utrzymania warstwy tynku. Dopiero przy gęstości $700 \mathrm{~kg} / \mathrm{m}^{3}$ ściana osiąga możliwą do przyjęcia wytrzymałość. Jednak grubość takiej ściany wynosiłaby ponad $70 \mathrm{~cm}$, a wartość współczynnika $\mathrm{U}=0,3 \mathrm{~W} / \mathrm{m}^{2} \mathrm{~K}$. Jest to grubość za duża $\mathrm{z}$ uwagi na okres schnięcia i tym samym niebezpieczeństwo zbutwienia wilgotnej słomy w deskowaniu oraz aktualną wartość współczynnika $\mathrm{U}=0.25 \mathrm{~W} / \mathrm{m}^{2} \mathrm{~K}$. Dlatego opcją dla gliny lekkiej jest glina $\mathrm{z}$ dodatkami porowatymi np. keramzyt, szkło porowate lub pumeks.

Przykładem budynku wykonanego z gliny lekkiej jest budynek mieszkalny powstały około 1994 roku w Karniowicach, obecnie w województwie małopolskim (rys.2). Pierwszym etapem budowy było wykonanie fundamentów w technologii tradycyjnej. Potem na warstwie hydroizolacji powstał szkielet drewniany, który wypełniono gliną lekką (rys.3). Następnie tak przygotowane ściany 
otynkowano 3 centymetrowym tynkiem z gliny. Uzyskano grubość ściany zewnętrznej $55 \mathrm{~cm}$ co przy obowiązującym wówczas współczynniku $\mathrm{U}=0,55 \mathrm{~W} / \mathrm{m}^{2} \mathrm{~K}$ spełniało ówczesne wymogi izolacyjności termicznej ścian (tabe-

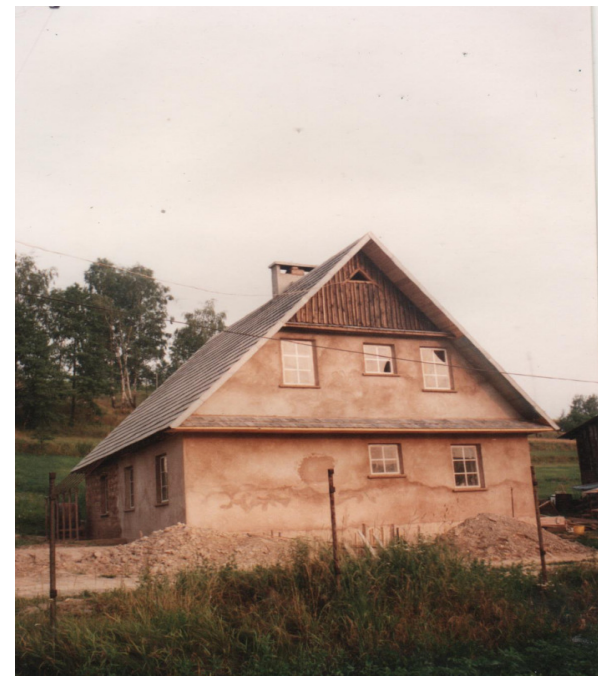

Rys. 2. Dom z gliny lekkiej w Karniowicach małopolska - 1994 rok

Fig. 2. House made from light clay in Karniowice - malopolska voivodeship 1994

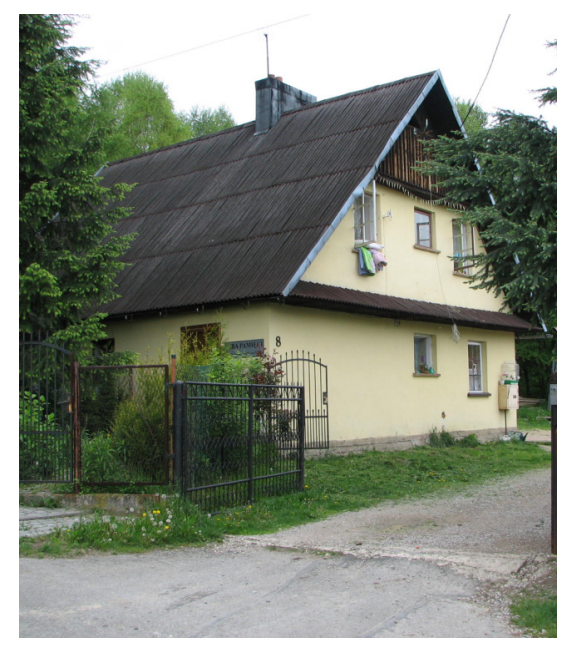

Rys. 4. Dom z gliny lekkiej w Karniowicach małopolska $2016 \mathrm{r}$.

Fig. 4. House made from light clay in Karniowice - malopolska voivodeship - 2016

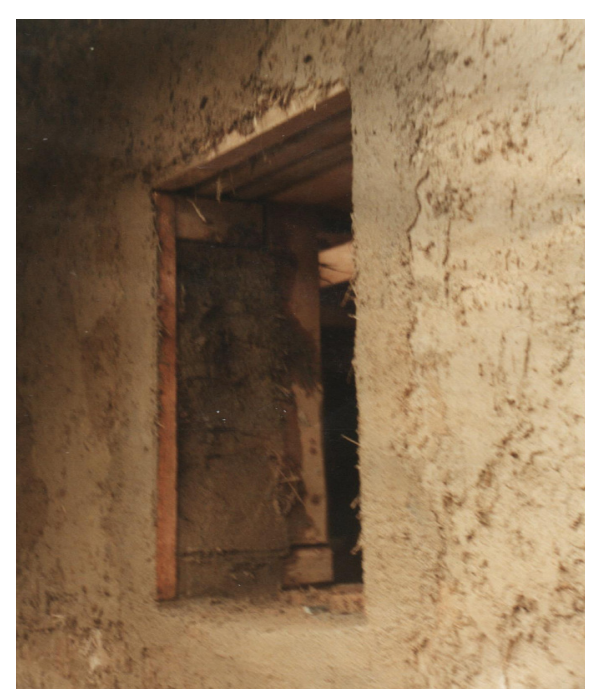

Rys. 3. Ściana w technologii z gliny lekkiej stan surowy $1994 \mathrm{r}$

Fig. 3. Wall made from light clay's technology raw state 1994

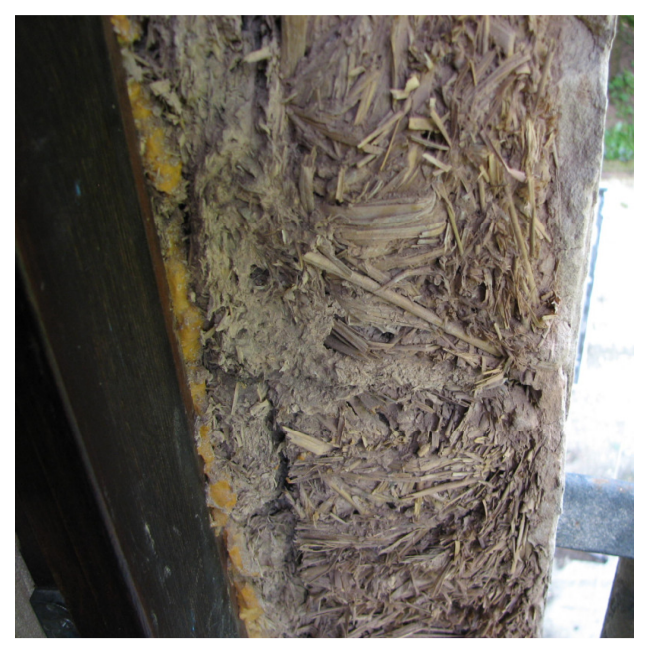

Rys. 5. Odsłonięty fragment $\mathrm{z}$ gliny lekkiej 2016 r.

Fig. 5. Bare part of wall made from light clay 2016 
la 1). Omawiany budynek mieszkalny jest obecnie użytkowany (rys.4), a mając ponad 20 lat jest w dobrym stanie technicznym. Ściana zewnętrzna nie wykazuje (rys.5) kurczenia się materiałów wypełniających, co spowodowałoby powstanie np. mostków termicznych, które w konsekwencji mogłyby spowodować zawilgocenie ściany. Wszystkie źdźbła słomy są dokładnie otoczone gliną, co świadczy o dokładnym zmieszaniu składników. Jak widać na powyższym przykładzie budynki budowane w tej technologii spełniają swoje założenia zarówno ekologiczne jak również ekonomiczne. Jednak przy obecnych zwiększonych wymaganiach ochrony cieplnej budynków (tabela1) ściany zewnętrzne musiałyby być szerokie, co znacznie zmniejsza ich zastosowanie w nowoczesnym budownictwie. Dlatego też najwłaściwszym sposobem budowania $\mathrm{z}$ gliny w polskich realiach jest budownictwo z kostek słomianych, tynkowanych gliną w systemie modularnym.

\subsection{Metoda $\mathrm{z}$ kostek słomianych tynkowanych gliną - system modularny}

Metoda wznoszenia budynków z bloczków słomianych i gliny jest jedną z najbardziej znanych i rozpowszechnionych w świecie w wielu wariantach. Często nazywana metodą glinosłombeli. Bezpieczeństwo konstrukcji zapewnia typowa struktura drewniana w dowolnie przyjętej formule. Słoma pełni jedynie funkcję izolacyjną (termiczną i akustyczną) oraz wypełniającą, którą następnie trzeba otynkować. Postępowym wariantem jest technika oparta na skonstruowaniu gotowych modułów o konstrukcji ramowo-drewnianej, którą następnie można składać w dowolne kształty. Szkielet drewniany zapewnia bezpieczeństwo konstrukcji, natomiast słoma pełni funkcję izolacyjną, wypełniając wewnętrzną przestrzeń modułu. Po wypełnieniu całego modułu słomą, powleka się go kilkucentymetrową warstwą gliny, tynku wapiennego lub okładziną drewnianą. W zależności od wielkości modułów wykonywanych na placu budowy metodą warsztatową lub metodą przemysłową, różnych detali montażu, lokalnych rozwiązań wypełnienia, stężania, tynkowania lub osłaniania innymi materiałami wykończeniowymi, możemy wyróżnić następujące systemy modularne ścian z kostek słomy :

- System Austriacki ,- System MODCELL,- System GREB itd.

Moduły drewniano-słomiane można wykorzystać w różnych typach budynków np.: mieszkalnych, gospodarczych. Można z nich tworzyć budynki parterowe lub piętrowe w nowoczesnej formie architektonicznej. Opracowany system pozwala na użycie sprasowanej kostki słomianej, również do konstrukcji dachów oraz podłóg. Plusem tego systemu jest możliwość przygotowania segmentów z wyprzedzeniem. Natomiast minusem pomimo stosowania taniej słomy jest cena konstrukcji drewnianej modułu.

\section{Podsumowanie}

Nasilenie budownictwa z gliny i słomy, w szczególności technologii strawbale, jest bardzo ciekawą perspektywą o silnym aspekcie ekologicznym. Domy wykonane $w$ tej technologii mogą nie tylko spełniać rygory niskiego zużycia 
energii w fazie eksploatacji, ale przede wszystkim nie wymagają zużycia dużej energii w fazie pro dukcji materiałów i wykonania obiektu. Rozpowszechnienie tej technologii może w znaczący sposób przyczynić się do redukcji emisji zanieczyszczeń gazowych i odpadów, a także emisji hałasu, wibracji promieniowania. Brakuje jednak uregulowań prawnych w zakresie technologii straw-bale w Polsce, co znacznie ogranicza jej rozwój.

\title{
Literatura
}

[1] Minke G.: Handbuch Lehmbau: Baustoffkunde , Techniken, Lehmarchitektur Verlag: Ökobuch Verlag, Erscheinungsjahr:2009.

[2] Kelm T.: Architektura ziemi. Tradycja i współczesność.1996. Oficyna Wydawnicza Politechniki Warszawskiej, Warszawa 1996 r.:132.

[3] „Mała Encyklopedia Rolnicza”.1964. Państwowe Wydawnictwo Rolnicze i Leśne. Warszawa 1964r.:1001.

[4] Adamczyk F., P. Frąckowiak., K. Mielec ,Z. Kośmicki . 2005. „Problematyka badawcza w procesie zagęszczania słomy przeznaczonej na opał”. Journal of Research and Application in Agricultural Engineering, 50(4):4-7.

[5] Tytko Ryszard.2009.,, Odnawialne źródła energii: wybrane zagadnienia”. OWG, Warszawa 2009r.:337.

[6] http://fasba.de/index.php?option=com_content\&task=view\&id=206\&Itemid=325, \{dostęp 1.06.2016\}.

[7] Z-23.11-1595 (03.06.2014) Wärmedämmstoff aus Strohballen „Baustrohballen“. All gemeine bauaufsichtliche Zulassung. Deutsches Institut für Bautechnik: 9.

[8] http://www.compaillons.eu/blog-rfcp/articlelemoniteurfr, \{dostęp 1.06.2016\}.

[9] http://www.modcell.com/files/2712/8506/9649/balehaus_case_study.pdf \{dostęp 1.06.2016\}.

\section{INNOVATORY AND ECOLOGICAL CLAY'S BUILDING}

\begin{abstract}
S u m m a r y
In study shown natural building focused on crucial properties of ecological materials in reference to primary energy. Presented description of straw and clay as building material. Described two methods of rising houses made from clay, which are very popular in the word. There were special emphasis took under method of rising walls made of clay and straw in boarding, plastered clay, which were shown by the example house in Karniowice. Presented also rising structures made fron straw in innovatory method with wooden-straw method plastered clay.
\end{abstract}

Keywords: natural building, clay, straw, primary energy

DOI:10.7862/rb.2016.196

Przestano do redakcji: 01.06.2016 $r$.

Przyjęto do druku: 30.11.2016 r. 